resolve this is in progress. Elliott (1964) reported that high doses of prednisolone given to patients with zoster of recent onset and severe pain led to a reduction of the duration of pain to an average of 3.5 days from an average of 3.5 weeks in untreated patients. Eaglstein et al. (1970) reported a similar effect from triamcinolone, though two elderly patients did not benefit. Though those writers did not report adverse effects, the potential hazard of the use of steroids in zoster-namely dissemination of the virus-has been emphasized by Merselis et al. (1964).

In very extensive zoster, such as generalized zoster in patients on immunosuppressive drugs and/or steroids, the local application may not be feasible, though Calabresi (1965) tried the use of systemic idoxuridine in very large doses, with equivocal results. In such patients the use of cytosine arabinoside, another antiviral drug, should be considered (Juel-Jensen, 1970b; Hall et al., 1970). At present, for the ordinary case of zoster the treatment outlined above appears to be of great benefit to the patients, and offers a real advantage in shortening the duration of that most dreaded of all consequences of zoster-pain.

Our thanks are due to Miss Ivy Poole, without whose devoted nursing expertise these trials would not have been possible; to
Mr. Ivor Chinn for his help with virus cultures; to Dr. A. H. Tomlinson for assay of varicella-zoster antibodies; to Dr. Alan Sharp and his colleagues for haematological investigations; to $\mathrm{Dr}$. M. M. Pickles for immunoglobulin assays; to Mr. J. R. P. O'Brien for biochemical investigations; and to Miss M. G. Craig, chief pharmacist, Radcliffe Infirmary, for her help.

REFERENCES

Calabresi, P. (1965). Annals of the New York Acadimy of Scienccs, 130, 192. Eaglstein, W. H., Katz, R., and Brown, I. A. (1970). Fournal of the American Medical Association, 211, 1681.

Elliott, F. A. (1964). Lancet, 2, 610.

Hall, T. C., Wilfert, C., and Jaffe, N. (1970). Transactions of the Association of American Physicians. In press.

Juel-Jensen, B. E. (1969). British fournal of Hospital M:dicine, 2, 1687.

Juel-Jensen, B. E. (1970a). Fournal of the American College Health Association. $18,227$.

Juel-Jensen, B. E. (1970b). British Mcdical fournal, 2, 154. Kligman, A. M. (1965). Journal of the American Medical Association, 193,

MacCallum, F. O., and Juel-Jensen, B. E. (1966). British Medical fournal, 2, 805 .

Mantel, N. (1967). Biometrics, 23, 65. Medicine, 113, 679 .

Rapp, F., and Vanderslice, D. (1964). Virology', 22, 321.

\title{
Cyanide Self-poisoning
}

\author{
M. LEE-JONES, ${ }^{\}$ M.B., M.R.C.P. ; M. A. BENNETT, $\dagger$ M.B., M.R.C.P. ; JANET M. SHERIWELL, $\ddagger$ B.SC., A.R.I.C.
}

\begin{abstract}
Summary: Four cases of cyanide self-poisoning were admitted to one hospital over a period of two years. Two of the patients died. The diagnosis in the unconscious patient may be suggested by the finding of bradycardia and the absence of cyanosis (despite inadequate ventilation). The diagnosis can be confirmed in 5 to 10 minutes by a simple test on gastric aspirate, performed by the casualty officer. Cardiac pacing was used in two patients and may have a place in the supportive management of severe cases.
\end{abstract}

\section{Introduction}

The diagnosis of cyanide poisoning is a matter of the utmost urgency if a lethal outcome is to be avoided. There are certain clinical features which may immediately suggest the diagnosis, but a simple and rapid confirmatory test would be most valuable.

The widespread industrial use of cyanides makes these compounds readily available for deliberate acts of self-poisoning, and sporadic cases are to be expected. Four such cases have been seen at this hospital in the past two years. This paper describes these briefly to illustrate some points of importance in the clinical diagnosis, and to suggest a simple biochemical examination which may be performed on gastric aspirate when confirmation of the diagnosis is required.

\footnotetext{
* Sheldon Clinical Rescarch Lellow; Honorary Senior Registrar in Toxicologv.

+ Research Fellow in Cardiology

¥ Senior Biochemist, The General Hospital, Birmingham 4.

l'resent address: Dudley Road, Hospital Birmingham 18.
}

\section{Case Reports}

Case 1.-A 25-year-old man arrived at the accident and emergency department at midnight, deeply unconscious. $\mathrm{He}$ was pulseless and apnoeic, but the skin was warm and the mucous membranes were pink. He was in cardiac asystole and, because cardiac action was not restored by external cardiac massage and intravenous isoprenaline, a transvenous bipolar pacemaker catheter was introduced into the right ventricle. Cardiac response to the pacemaker impulse was intermittent and he died 30 minutes after admission. Forensic examination showed cyanide in blood and tissues.

Case 2.-A 35-year-old man was found unconscious in the street at midday. On admission he was deeply unconscious, with fixed dilated pupils and absent deep tendon reflexes. The blood pressure was unrecordable, the heart rate 40 per minute. Though he was not cyanosed, respirations were shallow and infrequent. Ventilation was assisted manually via a cuffed endotracheal tube, and in view of the possibility of subarachnoid haemorrhage lumbar puncture was performed. Clear cerebrospinal fluid was obtained under normal pressure. Within minutes of completing this procedure cardiac asystole occurred; external cardiac massage restored a sinus bradycardia of 28 per minute. Intravenous isoprenaline achieved a heart rate of $70-80$ per minute with a palpable radial pulse, but the chronotropic effect was transient. A transvenous pacemaker catheter was therefore introduced into the right ventricle and pacing begun. At this time a document was found in his clothing which was in the nature of a "suicide note," whereupon a presumptive diagnosis of cyanide poisoning was made. Treatment with $10 \mathrm{ml}$. of $3 \%$, sodium nitrite and $25 \mathrm{ml}$. of 50 "' sodium thiosulphate intravenously was started, but asystole recurred and the ventricle failed to respond to the pacemaker impulse. Forensic examination confirmed the presence of cyanide in the stomach and blood. It was subsequently discovered that the patient obtained the cyanide at his piace of work, a local chemical factory.

Case 3--A 25-ycar-old bacteriology technician took about $1 \mathrm{~g}$ 
of potassium cyanide, which he had acquired from the laboratory where he worked. On admission, 18 minutes later, he was drowsy but lucid and was retching. Heart rate was 120 per minute and regular; blood pressure $110 / 80 \mathrm{~mm} . \mathrm{Hg}$; respiratory rate 30 per minute. An ampoule of amyl nitrite was broken and inhaled, while intravenous sodium nitrite and sodium thiosulphate were prepared and administered. Gastric aspiration and lavage were then performed and a further $12.5 \mathrm{~g}$. of sodium thiosulphate was left in the stomach. He made an uneventful recovery. Cyanide was identified both in the gastric aspirate and in the bottle from which he drank.

Case 4--Following a major parental crisis a 14-year-old girl drank the contents of a bottle which she believed to be "medicine," but which was known by her mother to be a cyanide-containing solution recently acquired from the electroplating shop at which she worked. On admission, 12 minutes later, the girl was fully conscious and lucid, with a regular heart rate of 120 per minute and blood pressure of $110 / 70$. The same regimen of treatment was followed as in Case 3, and an uneventful recovery followed. Cyanide was identified in the gastric aspirate and "medicine" bottle, but the exact nature of the solution is not known.

\section{Rapid Detection of Cyanide}

A simple chemical test (summarized in the British Pharmacopoeia, 1953), based on the Prussian blue reaction, was used for the detection of cyanide in gastric aspirate. A few small crystals of ferrous sulphate are added to $5 \mathrm{ml}$. of gastric aspirate and just sufficient 20 ". sodium hydroxide solution added to precipitate the iron (4-5 drops). The mixture is boiled, cooled, and just acidified with $10 \%$ hydrochloric acid (8-10 drops). A greenish blue colour or precipitate, which intensifies on standing, indicates the presence of cyanide. The reaction is not obtained with barbiturates, phenothiazines, imipramine, benzodiazepines, or amitryptyline, nor is the positive colour reaction changed appreciably in the presence of these drugs in addition to cyanide. The presence of a mixture of salicylate and cyanide, however, results in the immediate appearance of the greenish blue "cyanide" colour, which is rapidly masked by the purple of the ferric-chloride-salicylate reaction. The purple colour is seen immediately in the presence of salicylate alone.

\section{Discussion}

The lethal dose of hydrocyanic (prussic) acid (HCN) is 50 mg., and of KCN is 0.2-0.5 g. (Locket, 1957; Graham, 1962; Thienes and Haley, 1964; Martindale, 1967). When amounts greatly above these are ingested or inhaled death may occur in 5 to 15 minutes, but after ingestion of smaller quantities death may not occur for one to four hours. In such cases there is initial headache, vomiting, hyperventilation, and tachycardia, followed by coma, hypotension, bradycardia, and respiratory arrest (Lancet, 1961). It is in these less severe cases that diagnosis must be made very rapidly, since cyanide is one of the few poisons for which a specific and effective antidote exists.

There are two clinical features of late cyanide poisoning which are of cardinal importance ("late" implying that the patient is already in coma, with hypotension and apparently inadequate ventilation). The first is the absence of cyanosis. Since cyanide inhibits the cytochrome oxidase system. oxvgen transport is blocked so that haemoglobin remains fully oxygenated. The second important sign is bradycardia, which was notable in Case 2. This is a frequently reported sign, and Wexler, Whittenberger, and Dumke (1947) found it to be a constant feature in four instances of fatal cyanide poisoning. These authors studied convicts during judiciary execution by exposure to HCN gas. All showed similar variations of heart rate; at five minutes there was atrioventricular dissociation, but sinus rhythm was restored by the end of the sixth minute, after which progressive slowing occurred to rates between 35 and 50 per minute. The preterminal rhythm in two subjects was sinus bradycardia, and in two complete atrioventricular block.

The diagnosis of the comatose, hypotensive, apnoeic patient with dilated pupils presents a difficult problem, but the associated features of bradycardia and the absence of cyanosis should lead to a consideration of cyanide poisoning. Poisoning by carbon monoxide may present a similar picture, including bradycardia and pink mucous membranes, but the history is of value in that the patient is usually found in circumstances which suggest the diagnosis. If the source of carbon monoxide is coal gas the odour is often detectable on the patient's breath and clothing; it is an odour which will not be confused with that of cyanide, though in none of our cases was the aroma of "bitter almonds" detected, even from the gastric contents.

Treatment has proved successful, even when cardiac asystole has occurred (Dall and Hannah, 1964) and when the patient has been unconscious for 55 minutes (Potter, 1950). In Case 2 the circulation was maintained by means of an intracardiac pacemaker, and this procedure may prove to be a useful adjunct to the supportive treatment. Dcfinitive treatment consists of ventilation with $100 \%$ oxygen (Dall and Hannah, 1964) and the intravenous administration of sodium nitrite and sodium thiosulphate (Chen and Rose, 1952, 1956), followed as soon as possible by gastric aspiration and lavage.

It is clearly not possible to predict the outcome in Cases 3 and 4 had treatment been withheld, but at least the former had ingested a lethal dose, since symptoms and signs of cyanide poisoning were already present. The value of immediatc administration of the specific antidote in early cases is thus evident, but unfortunately sodium nitrite is potentially dangerous, especially if administered to patients with cerebral haemorrhage or coronary thrombosis, either of which may have to be considered in the differential diagnosis. The search for a safer antidote continues, and preliminary reports (Bain and Knowles, 1967) suggest that cobalt ethylenediamine tetra-acetate (edetic acid) may be satisfactory, as it is both rapid in action and safe, but more experience is needed in its use before it can be recommended as the treatment of choice.

When the diagnosis is in doubt, therefore, it may be considered prudent to confirm the diagnosis before the administration of nitrites. Methods available for identification of cyanide in the blood are too time-consuming to be of value in the management of acute poisoning, but examination of the gastric aspirate by the method described will confirm the presence of cyanide in 5 to 10 minutes. By this method a $5 \%$ concentration of cyanide in gastric contents can be detected, a level which might be expected were as little as $50 \mathrm{mg}$. ingested on a full stomach. Since the reagents are stable they can be kept in the accident and emergency department with simple instructions easily followed by the house officer, thus reducing the time required to a minimum.

\section{REFERENCES} Bain, J. T. B., and Knowles, E. L. (1967). British Medical fournal, 2, 763.
Chen, K. K., and Rose, C. L. (1952). Fournal of the American Medical

Association, 149, 113.
Chen, K. K., and Rose, C. L. (1956). Fournal of the American Medical Association, 162, 1154 .

Dall, J. L. C., and Hannah, W. M. (1964). British Medical Fournal, 2, 33.

Graham, J. D. P. (1962). The Diagnosis and Treatment of Acute Poisoning. London, Oxford University Press.

Lancet, 1961, 1, 1391.

Locket, S. (1957). Clinical Toxicology. London, Kimpton.

Martindale's Extra Pharmacopocia, 1967, ed. R. G. Todd, 25th edn. London, Pharmaceutical Press.

Potter, A. L. (1950). British Fournal of Industrial Medicine, 7, 125.

Thienes, C. H., and Haley, T. J. (1964). Clinical Toxicology, 4th edn. London, Kimpton.

Wexler, J., Whittenberger, J. L., and Dumke, P. R. (1947). American Heart fournal, 34, 163. 